\title{
Transients in a wind-mill driven, two-speed, squirrel-cage induction generator
}

\author{
Jan Rusek \\ Chair of Electrical Machines \\ AGH University of Science and Technology \\ Al. Mickiewicza 30, 30-059 Krakow (Poland) \\ phone: +4812 6172897, fax: +4812 6341096, e-mail: gerusek@cyf-kr.edu.pl
}

\begin{abstract}
The most widespread generator in wind-mill installations is a doubly fed, slip-ring induction generator. The rotor circuit include a static converter allowing power flow in both directions: from the rotor by negative slip and to the rotor by positive slip. However, in small and medium wind power plants a simple, double-speed, squirrel-cage induction generator may be considered as a suitable alternative replacing a doublyfed slip-ring induction generator. The higher speed range would be predestined for normal operation, which, however, requires some minimum wind speed. If the wind is weaker, re-switching of the generator to the lower speed range would still secure some power output. Re-switching to other speed is, however, accompanied by heavy transients in currents, torque and power.

The aim of the contribution is to present the plots of instantaneous speed, torque current, power and voltage by adjusting the operation to strong, moderate and weak wind. The plots of the torque in the clutch may constitute a base for assessment mechanical stress in the gearbox and wind-mill blades.
\end{abstract}

\section{Key words}

two-speed induction generator, transients, simulation

\section{Introduction}

In small and medium power wind-mill power plants a simple, double-speed, squirrel-cage induction generator may be considered as a suitable option, much cheaper than the slip-ring rotor alterative accompanied by a static converter in the rotor circuit. The higher speed range would be predestined for normal operation, which, however, would require some minimum wind speed. If the wind is weaker, re-switching the generator to the lower speed range will still secure some power output. Re-switching is, however, accompanied by heavy transients in currents, torque and power.

The aim of the contribution is to present the plots of speed, torque, current, power and voltage by adjusting the operation to strong, moderate and weak wind. The waveform of the torque constitutes the base for assessment of the mechanical stresses in the driving train elements, such as clutch, gearbox and the wind mill blades.

The ratings of the double-cage induction generator analyzed are $45 / 132 \mathrm{~kW}, 12 / 4$ poles, $1000 \mathrm{~V}, 50 \mathrm{~Hz}$ and $4.5 \mathrm{kgm}^{2}$ of rotor inertia. The inertia of the wind mill, referred to the generator's shaft, was assumed to be 1.5 $\mathrm{kgm}^{2}$. The mechanical train between the wind mill and the generator was modeled via the nonlinear clutch located at the generator's shaft. Its stiffness was assumed to be $9000 \mathrm{Nm} / \mathrm{rad}$, with the non-linearity factor of 0.9 . The latter means that the torque transmitted by the clutch by half of the nominal torsion (that is the torsion referring to the nominal clutch torque) is $90 \%$ of the one which were transmitted if the clutch had linear characteristic.

\section{Scenario}

Fig. 1 shows the torque versus speed characteristics of the wind mill. Both, torque and speed, are referred to the generator's shaft.

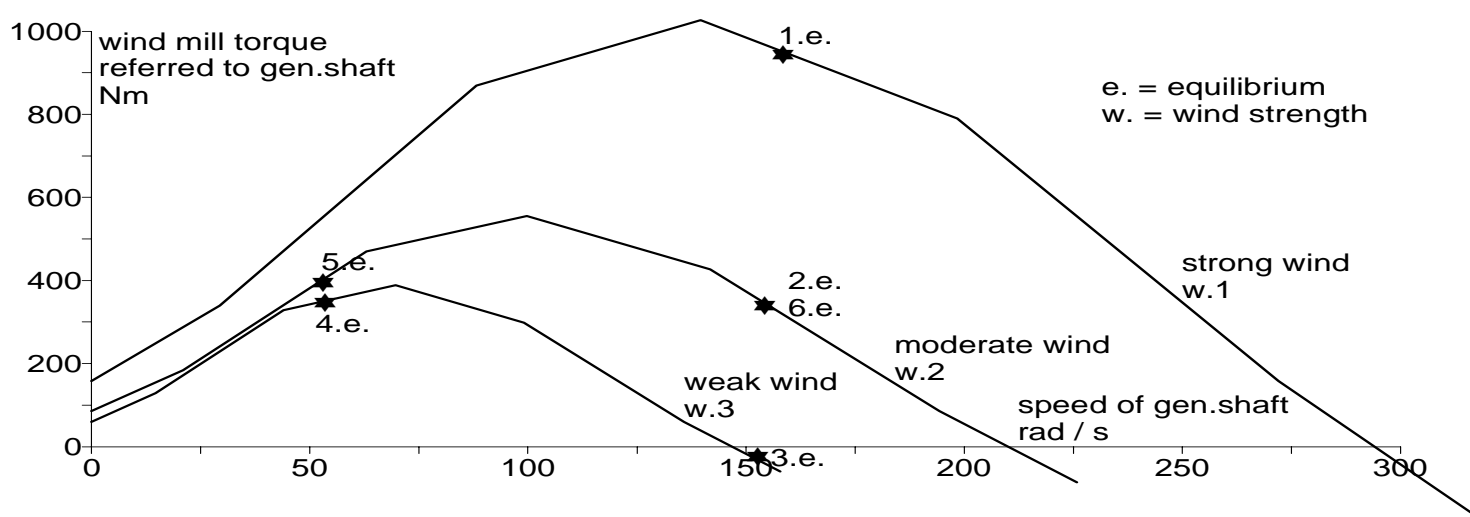

Fig. 1. Wind mill characteristics referred to generator's shaft, for three different speeds of the wind. 
The plots in Fig. 1 are piece-wise approximations of the real plots for strong, moderate and weak winds, as they are used in simulations [1].

The plots presented in next sections refer to the following scenario.

Initially, the generator is cut off from the grid and stands still. The wind is assumed to be strong (plot "w.1" in Fig. 1). The generating setup accelerates due to the wind. The acceleration of rotor speed changes accordingly to changes in the wind-mill characteristic "w.1" in Fig. 1.

At time point $\mathrm{t}=1.81$ seconds, the generator's speed reaches synchronous speed referring to the four-pole stator winding configuration. At this time point the fourpole winding is switched on the grid. After heavy switching-on transients in currents, torque and power, the equilibrium point "1.e" in Fig. 1 establishes, in which the four-pole winding secures power output of $147 \mathrm{~kW}$ to the grid. The power slightly exceeds the nominal power of $132 \mathrm{~kW}$.

At time point $\mathrm{t}=2.5$ seconds the wind is assumed to weaken down to moderate one, characterized by plot "w.2" in Fig. 1. After some meaningless transients the equilibrium establishes at point "2.e" in Fig. 1, with power output of $49.85 \mathrm{~kW}$, that is slightly lower than half of the nominal power.

At time point $\mathrm{t}=3$ seconds the wind diminishes further down to the one characterized by plot "w.3" in Fig. 1. After, again, some meaningless transients, in the equilibrium point "3.e", the still four-pole configured machine does not generate but consume the power of 9.8 $\mathrm{kW}$, drawn from the grid.

At time point $\mathrm{t}=3.5$ seconds the second winding, the 12pole one, is switched on to parallel operation together with the four-pole one. The heavy transients follow.

As can be seen form Fig. 7, now the four-pole winding draws the power from the grid. It is partially returned by the 12-pole winding back to the grid, what is seen in Fig. 8 . However, the net power is drawn from the grid. Surely, such a state of operation can be allowed to last only a fraction of a second.

After half a second interval of parallel operation, at time point $\mathrm{t}=4$ seconds the four-pole winding is switched off. The machine tends to the new equilibrium point "4.e" in Fig. 1, in which the 12-pole generator secures power output of $13.23 \mathrm{~kW}$ that constitutes, roughly, ten percents of the nominal power.

At time point $\mathrm{t}=5$ seconds the wind is assumed to strengthen again to the degree characterized by plot "w.2" in Fig. 1. The power output magnifies up to $15.8 \mathrm{~kW}$ (Fig. 8).

Finally, at time point $\mathrm{t}=5.5$ seconds, the simultaneous switching off of the 12-pole winding and switching on of the four-pole winding takes place. The heavy transients follow. In the new equilibrium point "6.e" in Fig. 1, the power output intensifies up to $49.85 \mathrm{~kW}$ (Fig. 7), similarly as in equilibrium point "2.e", what constitutes almost halt of the nominal power.

\section{Speed}

It can be seen in Fig. 2 that after 1.81 seconds the speed reaches the value of $157 \mathrm{rad} / \mathrm{sec}$, that is the synchronous value referring to magnetic field produced by the fourpole winding. Switching this winding on the grid prevents further acceleration of the rotor speed. The speed stabilizes at $159.07 \mathrm{rad} / \mathrm{sec}$, that is at the value a bit higher than the synchronous speed.

Then, by moderate wind, the speed is still oversynchronous, what secures power output.

By still weaker wind the speed decreases down to 156.96 $\mathrm{rad} / \mathrm{sec}$, that is down to the under-synchronous value, what prevents power generation. Only re-switching the stator winding to higher number of poles causes the generator's speed to fall down to $52.69 \mathrm{rad} / \mathrm{sec}$, which is a bit higher than the synchronous one referring to 12-pole flux and amounting to $52.35 \mathrm{rad} / \mathrm{sec}$. This secures power output even by this very weak wind.

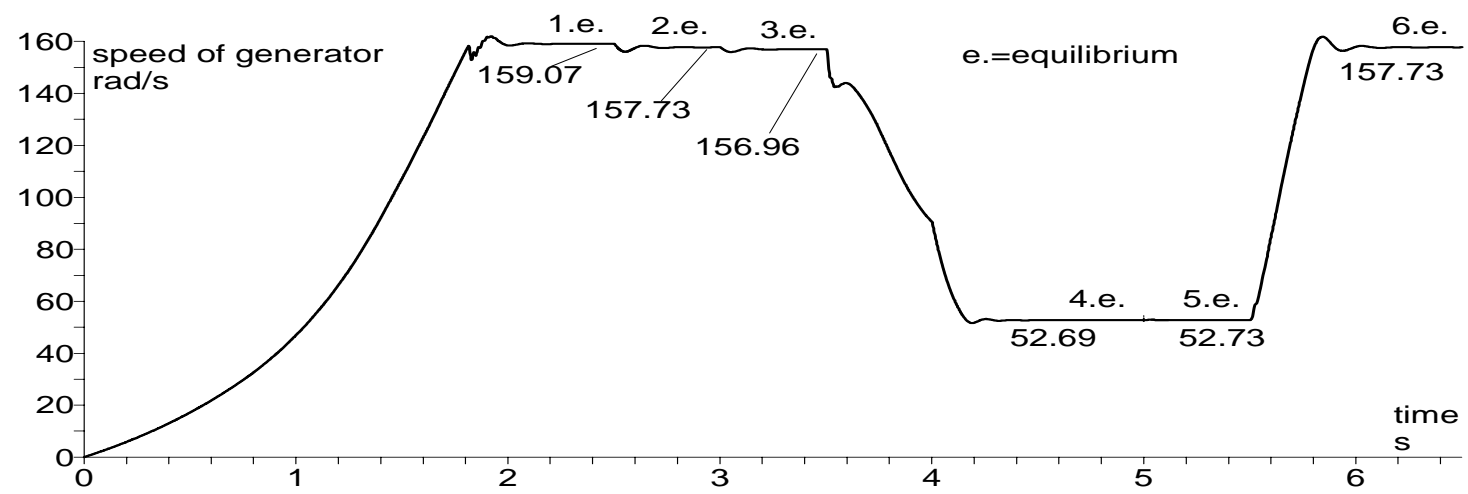

Fig. 2. Generator's speed during multistage re-switching scenario. The numbers indicate speed in equilibriums points. 


\section{Torque}

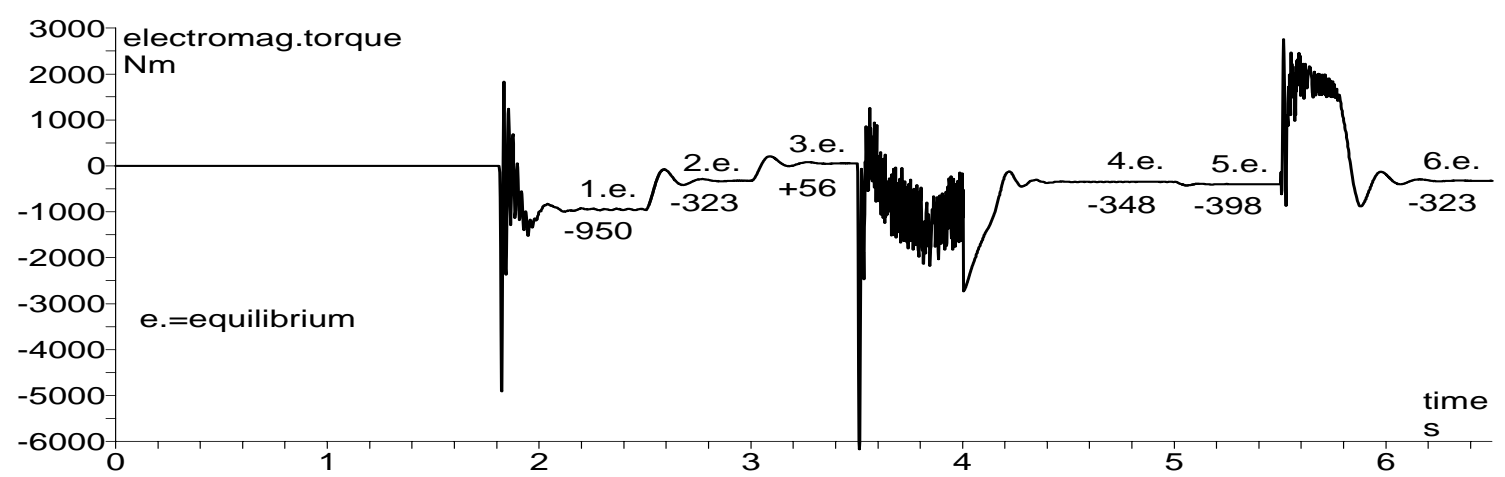

Fig. 3. Transients of generator's electromagnetic torque. The numbers indicate electromagnetic torque in equilibrium points.

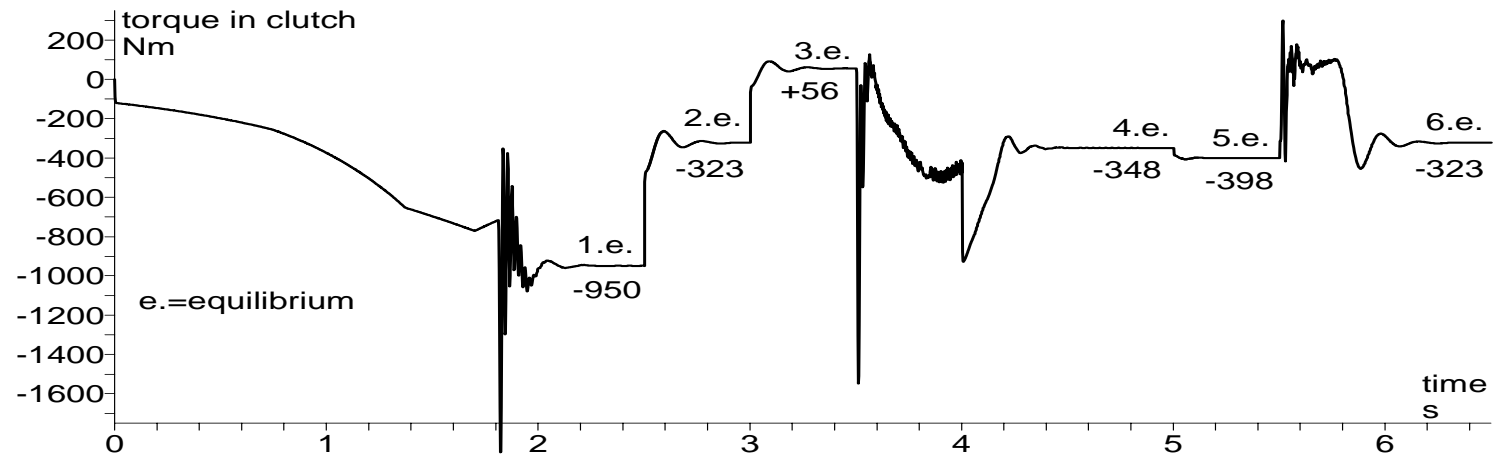

Fig. 4. Transients of the torque stressing the clutch. The numbers indicate in-the-clutch torque in equilibrium points.

The plots of the torque in Fig. 3 and 4 are similar, but not identical. The electromagnetic torque shows up more alternating components than that transmitted by the clutch. The maximums of the peaks in Fig. 4 are about four times smaller than those in Fig. 3. But they are still about three times bigger than the nominal torque of the motor, amounting to $877 \mathrm{Nm}$ by 12 poles and $855 \mathrm{Nm}$ by four poles. The peaks in the electromagnetic torque overpass the nominal torque by a factor of, approximately, seven.

\section{Current}

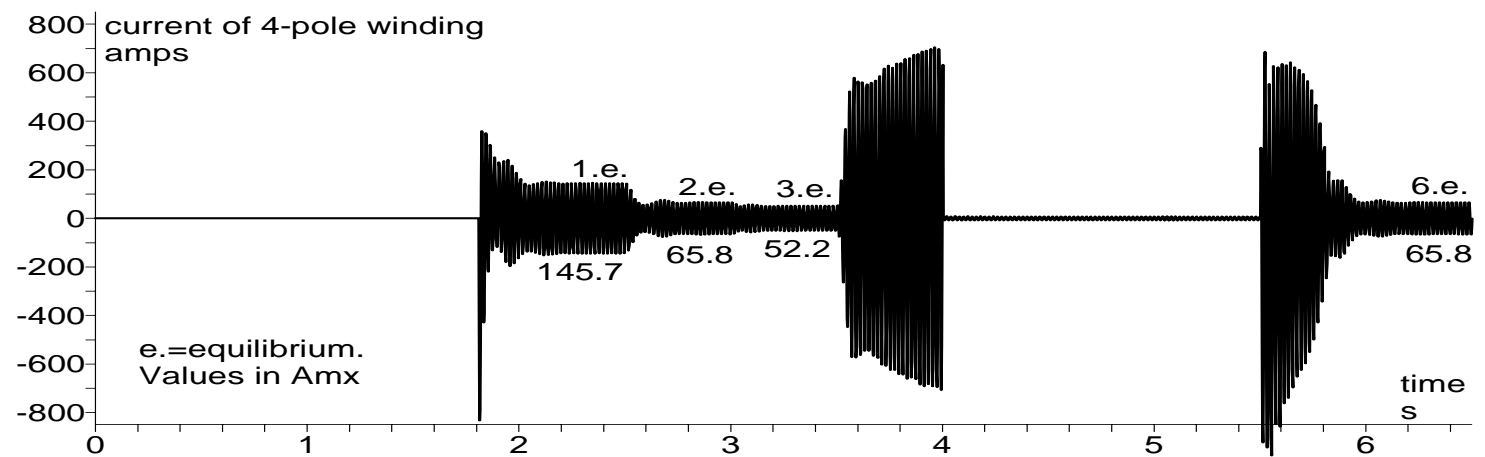

Fig. 5. Current of the stator winding four-pole section. The numbers indicate maximums of the current in equilibrium points.

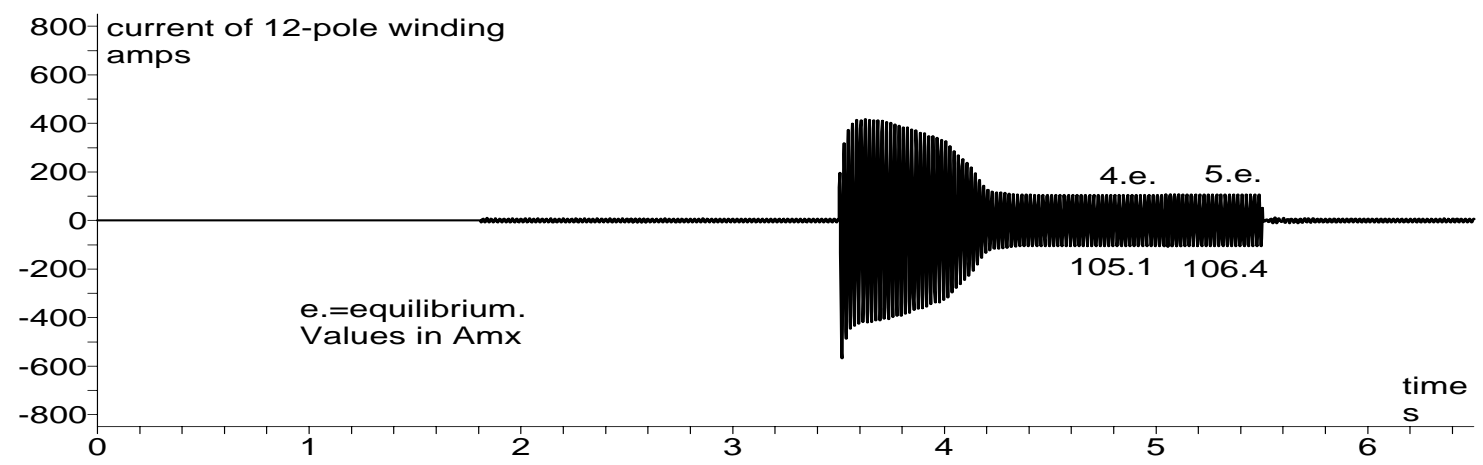

Fig. 6. Current of the stator winding 12-pole section. The numbers indicate maximums of the current in equilibrium points. 
In the time interval between 1.81 and 3.5 seconds, only the four-pole stator winding is active. The 12-pole winding remains open. In the equilibrium point "3.e" the generator operates at higher speed of $156.96 \mathrm{rad} / \mathrm{sec}$.

Setting the generator for operation at lower speed could be accomplished by switching the 12-pole winding for temporary parallel operation together with the four-pole winding, followed by switching off the four-pole winding. The parallel operation is accompanied by high current overloading, demanding prompt switching off the four-pole winding. This is accomplished by time point $\mathrm{t}=$ 4 seconds, what is seen in Fig. 5 and 6.

\section{Power}

It follows from Fig. 7 that until time point $\mathrm{t}=3$ seconds, the generator secures power output of first 147 and then $49.85 \mathrm{~kW}$. As expected the bigger power, amounting to $147 \mathrm{~kW}$, accompanies strongest wind, what is depicted by the equilibrium point "1.e" in Fig. 1. In equilibrium point "3.e" the power drawn by the machine is not negative, that is there is no power output from the windmill plant by weak wind (denoted in Fig. 1 as "w.3").

However, activating the 12-pole stator winding sets the generator into new equilibrium point "4.e", in which the power output by the same weak wind reaches $13.23 \mathrm{~kW}$. This is, roughly, ten percent of the nominal power. This is seen in Fig. 8.

Moderate wind, denoted in Fig. 1 as "w.2" intensifies power output up to $15.8 \mathrm{~kW}$ in equilibrium point "5.e" in Fig. 8.

Switching over the generator to higher speed range pushes the equilibrium point to "6.e" in Fig. 1. This, by the same wind, magnifies power output up to $49.65 \mathrm{~kW}$.
From economical point of view, the possibility of power generation by weaker winds is very important as the weak winds prevail.

\section{Voltage}

Up to the time point $\mathrm{t}=3.5$ seconds the only active winding is that producing four magnetic poles. The other winding, that is that able to produce 12 poles remains open. As can be seen in Fig. 9, within this time interval, the phase-to-phase voltage across the first winding is sinusoidal, as it is fixed by the grid.

However, due to magnetic couplings of the at-themoment active winding with that able to produce 12 magnetic poles, also across the 12-pole winding some residual voltage is being induced.

Principally, different number of poles of both windings prevent mutual inducement of the voltages due to the fundamental components of the flux.

However, higher harmonics due to specific coil distribution of both windings, as well as stator and rotor slotting, account for some residual coupling of these windings, despite different numbers of poles they use to produce. This residual coupling is responsible for the voltage seen in Fig. 10 up to the time point of 3.5 seconds.

The same refers to the time interval between 4 and 5.5 seconds in Fig. 9, but this time the switched-off four-pole winding is affected by the 12-pole one, which remains switched on the grid and hence is active.

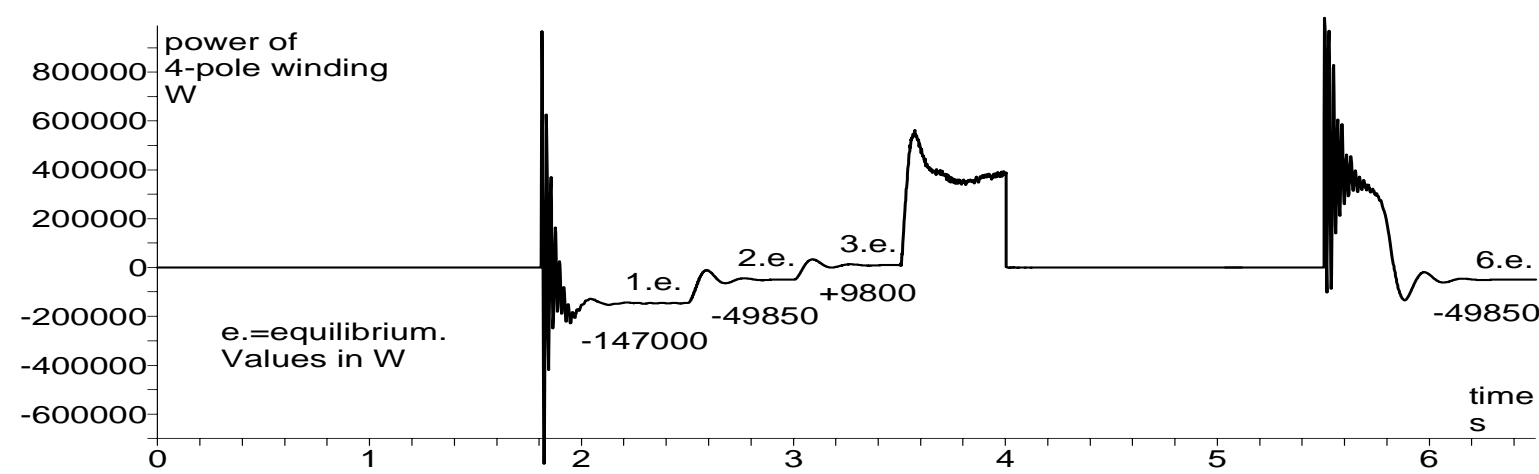

Fig. 7. Power of the stator winding four-pole section. The numbers indicate four-pole winding power in equilibrium points.

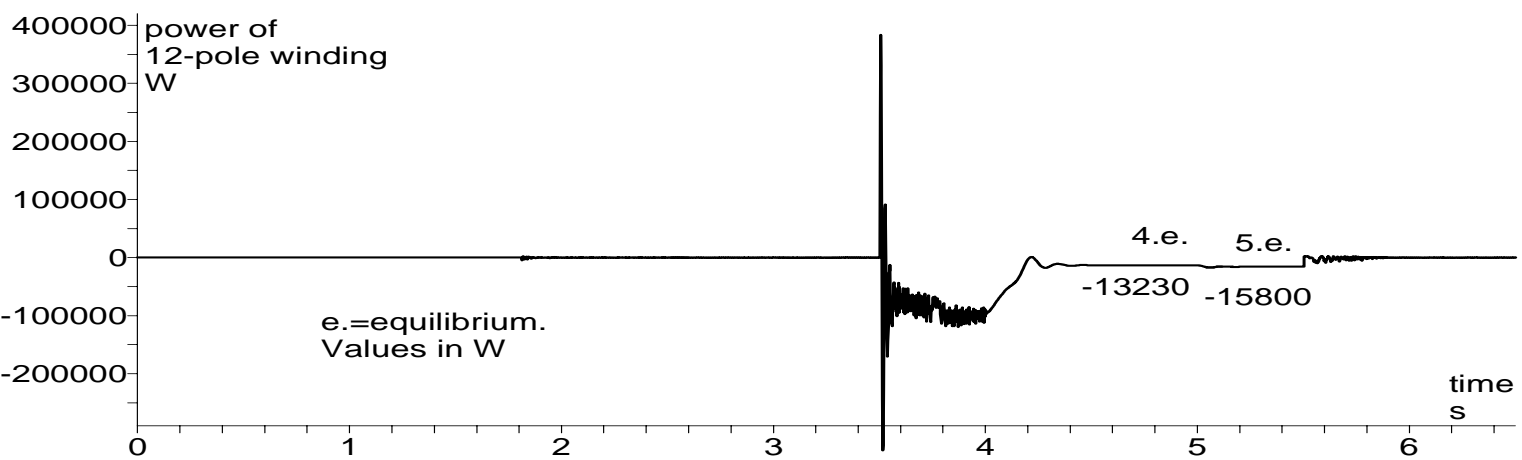

Fig. 8. Power of the stator winding 12-pole section. The numbers indicate 12-pole winding power in equilibrium points. 


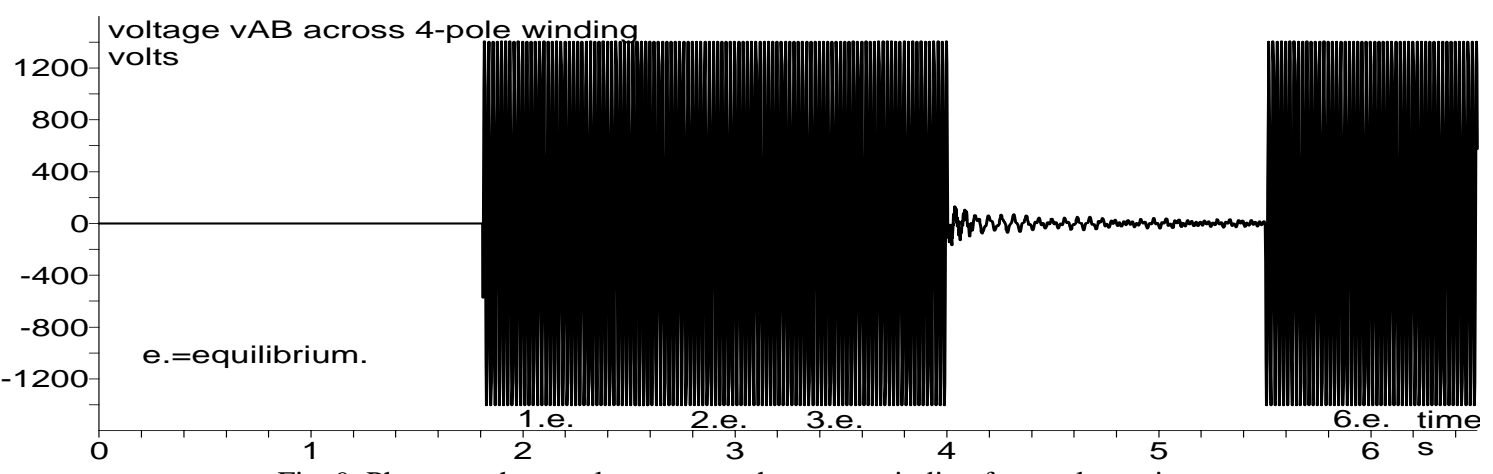

Fig. 9. Phase-to-phase voltage across the stator winding four-pole section.

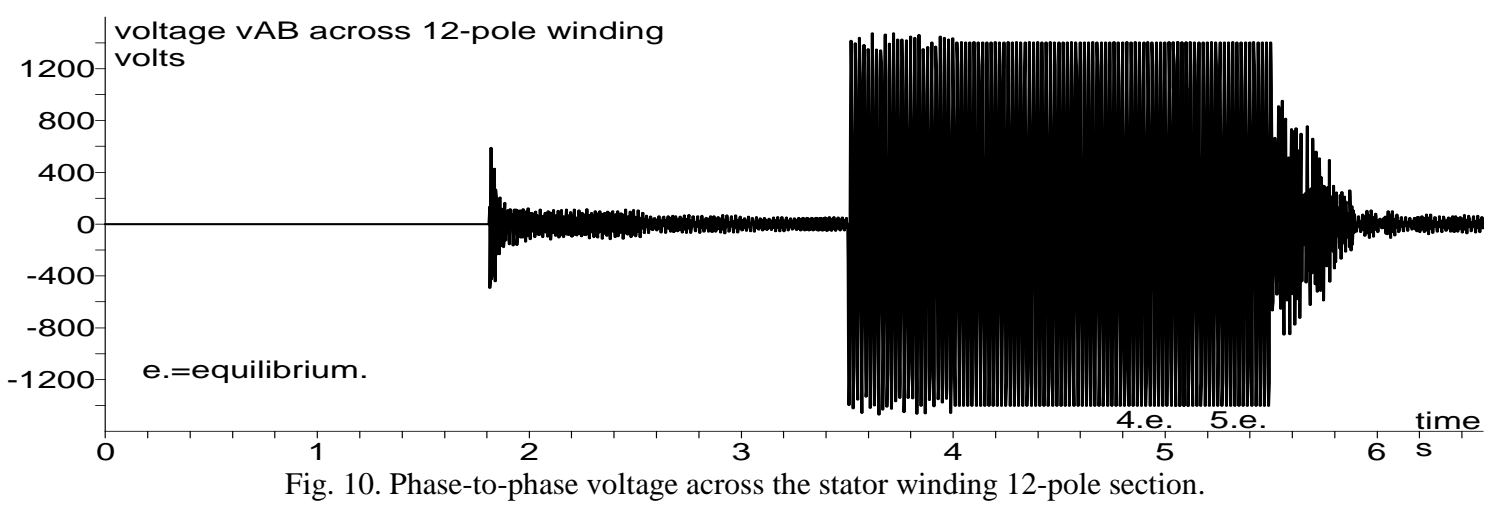

\section{Simulation method}

The simulation was based on the poly-harmonic model the implementation of which was originally presented in [2]. The application of its more advanced form for analysis of nonsymmetrical induction machine was presented in [3].

The model accounts for slotting, eccentricity and any actual stator winding configuration. Of importance for the present simulation was the possibility of accounting for true electromagnetic couplings between the two separate windings, the one able to produce four and the other 12 poles. Despite different number of poles produced by these windings, there is some residual mutual magnetic coupling between them, due to higher harmonics, leakage inductances and not full topological symmetry of each phase of one winding with respect to each phase of the other winding. Another words, there exist some topological asymmetry of mutual distributions of the branches of both windings, despite that both, the four and the 12 pole winding parts are, separately, perfectly symmetrical.

These residual couplings had their explicit consequences in the time interval between 3.5 and 4 seconds, that is when the two windings operate in parallel: the electromagnetic torque and the 12-pole winding power show up conspicuous alternating components visible in Fig. 3 and 8.

The possibility of mutual effecting the different-pole windings still worsens if the rotor of the generator would show up some eccentricity, whether static or dynamic one. This, though possible to investigate utilizing the software used for these simulations, falls beyond the scope of this paper.

The model, and its computer implementation, is general and is useful also e.g. by investigations of bearing failures. An example of such application is presented in [4]. The model constitute further development of the family of harmonic-balance based models [5], as it do not impose speed constancy.

The software consist of four programs. The first one calculates leakage inductances, that is those not depending on the rotor angular position. The second calculates inductances depending on the rotor angular position. The inductances of separate stator-winding coils are calculated in a numerical way for 523 rotor angular positions. For each rotor position a new set of magnetic flux channels in the air gap between stator and rotor is reestablished. Within each magnetic flux channel the magnetic flux density is assumed to change linearly. The lengths of magnetic lines within each magnetic flux channel account for instantaneous result eccentricity and stator and rotor slotting.

The same approach is made use of by calculations of the inductances of the rotor meshes constituted by adjacent cage bars.

The knowledge of the fluxes in magnetic flux channels is tantamount to the knowledge of flux distribution down the air gap between stator and rotor. This, in turn, allows calculation of flux linkages for any pair of stator coils, any pair of rotor meshes, and any pair constituted by a stator coil and a rotor mesh. These flux linkages are 
equivalent to mutual inductances of all the elementary circuits of the machine.

The third program calculates derivatives of all the self and mutual inductances, with respect to rotor angular position. This is indispensable as the calculation of the electromagnetic torque (in the next program) is based on these derivatives.

The forth (last) program performs numerical integration of differential equations describing the dynamics of both the machine and the wind mill mechanical section.

\section{Conclusions}

Application of a two-speed induction generator secures power output also by weak winds. This is of tremendous importance from the economical point of view, as weak winds are the ones which prevail.

However, the re-switching between the two stator winding parts is accompanied by heavy torque, current and power transients. Their impact on both the power system and plant setup must be examined scrupulously.

The plots presented in the contribution allow to predict the magnitude of the peaks of the torque in the clutch as well as the magnitude of the stator currents.
The impact on the mechanical side of the setup may be judged from Fig. 4. As expected, the peak stresses in the clutch (and thus also in the wind mill blades) are much smaller than the peaks in the electromagnetic torque. This, however, will always depend on the overall stiffness and inertia of the whole mechanical train between the generator and the wind mill. Hence, separate calculations should be carried out for each particular case of wind-mill driven generating setup.

\section{References}

[1] M. El. Mokadem, C. Nichita, B. Dakyo, W. Koczara, "Maximum wind power control using torque characteristic in a wind diesel system with battery storage", in Proc. ICEM2004, Vol. 2, pp. 661-662.

[2] J. Rusek., "Reflection of eccentricities in spectral composition of currents of induction machines", in Proc. ICEM1996, Vol. 2, pp. 470-475.

[3] J. Rusek, "Computer implementation of the induction machine dynamical model accounting for broken bars, eccentricities, slotting and parallel branches", in Proc. ICEM2000, Vol. 2, pp. 868 - 872.

[4] J. Rusek, L. Swedrowski, "Induction machine model for current diagnostics of bearings", in Tagungsband 48.Internationales Wissenschaftliches Kolloquium 2003, Ilmenau, pp. 607 - 608.

[5] J. Rusek, "Categorization of induction machines in current signature analysis". Electrical Engineering, Vol. 84, No. 5, pp. 265 - 273, December 2002. 